\title{
On the Variations of the Muscle Flexor Digitorum Brevis: Anatomical Insight
}

\author{
Variaciones del Músculo Flexor Corto de los Dedos: Experiencias de Anatomía
}

Isurani Ilayperuma

ILAYPERUMA, I. On the variations of the muscle flexor digitorum brevis: anatomical insight. Int. J. Morphol., 30(1):337-340, 2012.

SUMMARY: Flexor digitorum brevis, an intrinsic muscle of the sole of the foot, is stated as one of the muscles that shows frequent anatomical variations. Its most commonly reported anomaly is the absence of tendon to the little toe. From a clinical standpoint of view, flexor digitorum brevis musculocutanous flap is used in the reconstruction of the heel pad and flexor digitorum brevis tendon transfer is employed in the correction of flexible claw and hammer toe deformities. Despite its significance little is known regarding the variations of this muscle in Sri Lankans. Hence, the goal of this study was to elucidate the incidence and morphological features of this muscle in an adult Sri Lankan population. A total of one hundred and thirty five apparently healthy human feet were dissected and studied for the morphological features of the flexor digitorum brevis muscle. The incidence of the absent fourth tendon of the flexor digitorum brevis in the present study was found to be $71.85 \%$. In all cases, when absent, it was missing bilaterally. The results of the present study further highlight the anatomical variations of the flexor digitorum brevis muscle. A sound knowledge about the anatomical variations of flexor digitorum brevis will facilitate the outcome of surgical as well as diagnostic imaging techniques of the foot. Furthermore, understanding muscle architecture of the foot may assist in the design of prosthesis and analysis of foot function.

KEY WORDS: Flexor digitorum brevis; Anatomical variation; Sri Lankan.

\section{INTRODUCTION}

Flexor digitorum brevis is an intrinsic muscle of the sole of the foot that lies immediately superior to the central part of the plantar aponeurosis and inferior to the tendons of flexor digitorum longus. Its flat spindle shaped muscle belly arises as a thin tendon from the medial process of tuber calcanei, proximal part of plantar aponeurosis, intermuscular septa and other adjacent fascial layers. The muscle fibers converge anteriorly forming four tendons, one each for the four lateral toes. At the base of the proximal phalanges, each tendon of the flexor digitorum brevis, splits into two slips and spirals around the tendons of the flexor digitorum longus, reunites in a chiasma, divides again and inserts into the margins of the intermediate phalanges of lateral four toes. The tendons of the flexor digitorum brevis enter fibrous digital tunnels on the plantar aspect of the digits, where they are surrounded by digital synovial sheaths. These fibrous digital tunnels or sheaths hold the flexor digitorum brevis tendons to the bony plane and prevent them from bowing when the toes are flexed (Romanes, 1986; Williams et al., 2000).
Flexor digitorum brevis is innervated by the major sensory nerve in the sole of the foot, medial plantar nerve, a branch of the tibial nerve and vascularized by medial and lateral planter arteries, plantar metatarsal arteries and plantar digital arteries (Williams et al.). Flexor digitorum brevis function in flexion of the four lateral toes at the proximal inter-phalangeal and metatarso-phalangeal joints, regardless of the position of the ankle joint (Romanes; Williams et al.). Along with other muscles of the foot, it reinforces the longitudinal arch of the foot (Romanes; Rosse \& GaddumRosse, 1997). Paralysis of the flexor digitorum brevis results in distortion of the arches of the foot (Rosse \& GaddumRosse).

Variety of anatomical variations of the flexor digitorum brevis that differed from classical descriptions given in Anatomy texts has been reported. Variation in this muscle occurs in $63 \%$ of foots (Bergman et al., 1988). Some of its' reported anomalies have been manifested as the absence of tendon to the little toe (Nathan \& Globe, 1974;

Department of Anatomy, Faculty of Medicine, University of Ruhuna, Sri Lanka. 
Bergman et al.; Chaney et al.,1996; Claassen \& Wree, 2003; Yalçin \& Ozan, 2005; Lobo et al., 2008; Becerro de Bengoa Vallejo et al., 2008), presence of a deep head arising from the flexor digitorum longus which either joins the main muscle or proceeds as a separate tendon to the little toe (Bergman et al.), it is present but ends in fascia, failing to reach the toe, it arises separately from the fibular band of the plantar aponuerosis and presence of supernumerary slips (Rosse \& Gaddum-Rosse).

From a clinical standpoint of view, flexor digitorum brevis musculocutanous flap is used in the reconstruction of the heel pad and flexor digitorum brevis tendon transfer is employed in the correction of flexible claw and hammer toe deformities. Therefore, an in depth knowledge of the anatomical variations of this muscle will facilitate preoperative diagnosis as well as the surgical procedures of the foot.

Despite its' significance little is known regarding the occurrence of variations of this muscle in Sri Lankans, inhabitants of the South Asian country. Hence, this study was carried out to elucidate the incidence and morphological features of flexor digitorum brevis muscle in an adult Sri Lankan population.

\section{MATERIAL \& METHOD}

This study was carried out on a total of one hundred and thirty five apparently healthy human cadavers ( 81 males and 54 females) during routine gross anatomy dissections in the Department of Anatomy, Faculty of Medicine, University of Ruhuna, Galle, Sri Lanka. The cadavers were preserved in $10 \%$ formalin. The age group of the cadavers varied between 48-67 years.

All feet $(n=270)$ were carefully examined to ensure the absence of any physical deformities or trauma. Dissections of the feet were performed as follows (Romanes, 1986): A longitudinal incision was made on the sole of the foot extending from heel to toes. The planter skin, subcutaneous fat and fascia

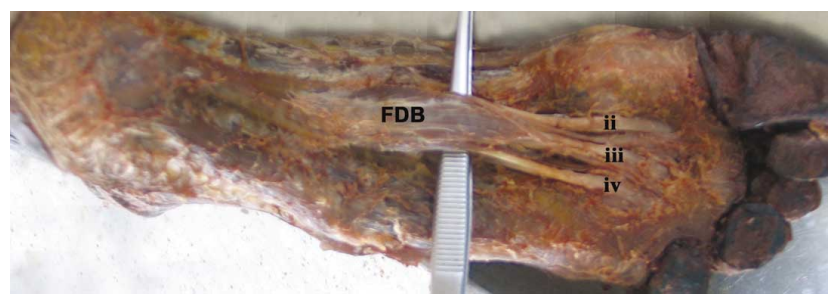

Fig. 1. Plantar surface of the left foot demonstrating the muscle belly of the flexor digitorum brevis (FDB) and its 3 tendons to the 2nd (ii), 3rd (iii) and 4th (iv) toes. and planter aponurosis of the foot were dissected carefully to expose the full length of the flexor digitorum brevis from its proximal to distal attachment.

\section{RESULTS}

Out of 270 lower limbs of 135 cadavers, fourth tendon of the flexor digitorum brevis was absent bilaterally in 194 lower limbs of 67 cadavers (Fig. 1). Supernumerary tendons were absent in all the cadavers. The incidence of the absent fourth tendon in the present study was found to be $71.85 \%$.

In all the study subjects, the origin and insertion of the flexor digitorum brevis conformed to the standard text book descriptions (Williams et al.). The muscle was shown to arise from the medial process of tuber calcanei, plantar aponeurosis and intermuscular septa of adjacent muscles. It divided into either three $(71.85 \%)$ or four parts $(28.15 \%)$ which ended in slender tendons to the second, third and forth or fifth toes.

\section{DISCUSSION}

The present study documents valuable new data on the anatomical variations of the muscle flexor digitorum brevis in an adult Sri Lankan population.

Although a wide variety of anatomical variations such as, absence of flexor digitorum brevis slip to a given toe, presence of supernumerary slips or its replacement by a slip from the long flexor tendon or flexor accessorius have been reported (Nathan \& Globe; Bergman et al.), the absence of flexor digitorum brevis tendon slip to the fifth toe was stated as the commonest anatomical variation of this muscle (Nathan \& Globe; Chaney et al.; Claassen \& Wree; Yalçin \& Ozan; Lobo et al.; Becerro de Bengoa Vallejo et al.). It is interesting to note, that the incidence of absence of flexor digitorum brevis slip to the little toe was reported as 63\% (Nathan \& Globe), 21\% (Bergman et al.), 18\% (Yalçin \& Ozan) and 100\% (Lobo et al.) among different study populations.

The present study reports that flexor digitorum brevis slip to the little toe was absent in $72 \%$ of the study subjects, a result that further highlights the anatomical variations of flexor digitorum brevis. Such anatomical variations, remind us to appreciate the crucial concept that anatomical diversity and variation is a canon of living organisms.

However, it is not clear whether these variations represent a functional adaptation of the reference populations. 
Phylogenetic considerations suggest that quadratus plantae, another muscle in the sole of the foot, is becoming bulkier, implying its significance in human locomotion (Sooriakumaran \& Sivananthan, 2005). Evidence suggests that quadratus plantae functions to resist extension of the toes during the stance phase of locomotion, which serves to increase the stability of the foot (Sooriakumaran \& Sivananthan).

The usage of the fifth toe in humans is minimal when compared to the little finger. Further, it has no opposition action in humans (Williams et al.). Thinking along these lines, it has been speculated, that muscles acting on the little toe are undergoing evolutionary changes (Lobo et al.). This is further supported by the results obtained from an electromyographic investigation of foot muscles that reports, three toe flexors (flexor digitorum longus, flexor digitorum brevis and flexor accessorius) act together to resist extension of the toes during the stance phase of locomotion. Despite the large flexor accessorius in humans, neither it nor the flexor digitorum brevis were preferentially recruited over the flexor digitorum longus for any normal posture or locomotion (Reeser et al., 1983).

Human foot has evolved from a primarily a grasping organ which was essential for efficient arboreal locomotion and over the course developed to have an elaborate plantar aponeurosis, strong plantar ligaments, longitudinal arches, an enlarged musculus flexor accessorius, an adducted (nonopposable) hallux, a remodeled calcaneocuboid joint, a long tarsus, and shortened toes (II to V) (Susman, 1983). It serves a dual role in bi-pedal locomotion performing as a mobile structure and also as a rigid lever (Williams et al.). Theories about the functions of the foot muscles have centered on their role in arch support. Arches of the foot are normally maintained by bones and ligaments. The foot muscles play an important role in positioning of the forces on the foot in both posture and locomotion (Williams et al.).

From a clinical standpoint of view, knowledge about anatomical variations of flexor digitorum brevis has several implications. Claw toe deformity is characterized by dorsiflexion of the metatarso-phalangeal joint and plantar flexion of the proximal and distal inter-phalangeal joints (Becerro de Bengoa Vallejo et al.). Flexor digitorum longus tendon transfer is considered as the gold standard and transfer of the flexor digitorum brevis as an alternative method to treat such deformities (Becerro de Bengoa Vallejo et al.). In the correction of claw or hammer toe deformities, especially in the second, third, and fourth toes, flexor digitorum brevis tendon has been successfully transferred to the dorsum of the proximal phalanx (Becerro de Bengoa Vallejo et al.). Furthermore, results obtained from a study that compared the biomechanical outcome of these two methods by means of finite-element simulation have shown that, flexor digitorum brevis tendon transfer resulted in a more uniform distribution of stress along the entire toe. These results confirm that flexor digitorum brevis tendon transfer as an effective treatment option for patients with claw toe deformity (García-González et al., 2009).

Curly toe is a common congenital deformity characterized by flexion and varus deformity of the inter-phalangeal joints. Flexor digitorum brevis tendon has also been successfully employed in the surgical correction of this condition (Tokioka et al., 2007).

A rotational transfer of a musculocutaneous island flap comprising of the flexor digitorum brevis muscle is considered as one of the best procedures currently available for covering and reconstructing the weight-bearing area of the heel (Hartrampf et al., 1980; Ikuta et al., 1984; Stevenson et al., 1985; Lin et al., 1991). In addition, distal plantar area of the foot has been successfully reconstructed using a flexor digitorum brevis muscle flap based on reverse-flow lateral plantar artery pedicle (Sakai et al., 2001). This has important implications as it is difficult to resurface skin defects of the sole because of its unique anatomy.

Taken together, it is clear that a sound knowledge about the anatomical variations of flexor digitorum brevis will facilitate the outcome of surgical as well as diagnostic imaging techniques such as computed tomography and magnetic resonance imaging of the foot. Understanding muscle architecture of the foot may assist in the design of surgical procedures such as tendon transfer, biomechanical modeling of the foot, prosthesis design and analysis of foot function.

ACKNOWLEDGEMENT. The author wishes to acknowledge Dr. R. Goonathilaka, for helping with the dissections and Mrs. N. Palahepitiya for technical assistance.

ILAYPERUMA, I. Variaciones del músculo flexor corto de los dedos: experiencias de anatomía. Int. J. Morphol., 30(1):337-340, 2012.

RESUMEN: El músculo flexor corto de los dedos, es un músculo intrínseco de la planta del pie que frecuentemente presenta variaciones anatómicas. La variación más frecuente es la ausencia de tendón destinado al dedo mínimo. Desde el punto de vista clínico se utilizan colgajos musculocutáneos del músculo flexor corto de los dedos para la reconstrucción de la región subcalcánea. Además, el tendón del músculo es usado para corregir deformidades de garra y martillo de los dedos del pie. A pesar de su importancia, es escasa la información acerca de este músculo en la población adulta de Sri Lanka. Fueron disecados 135 pies humanos aparentemente sanos analizándose sus características morfológicas. Se determinó que un $71,85 \%$ el tendón para el 
quinto dedo del músculo flexor corto de los dedos estaba ausente. En todos los casos, ésta se presentaba bilateralmente. El estudio señala la importancia de tener un cabal conocimiento acerca de las variaciones anatómicas del músculo flexor corto de los dedos, para facilitar tanto las técnicas quirúrgicas, como el diagnostico a través de imagenlogía del pie. Además, un buen conocimiento de la arquitectura muscular del pie puede ayudar en el diseño de prótesis y en el análisis de la función del pie

PALABRAS CLAVE: Músculo flexor corto de los dedos; Variación anatómica; Cingaleses.

\section{REFERENCES}

Becerro de Bengoa Vallejo, R.; Viejo Tirado, F.; Prados Frutos, J. C.; Losa Iglesias, M. E. \& Jules, K. T. Transfer of the flexor digitorum brevis tendon. J. Am. Podiatr. Med. Assoc., 98:2735,2008 .

Bergman, R. A.; Thompson, S. A.; Afifi, A. K. \& Saadeh, F. A. Compendium of Human Anatomic Variations. Baltimore, Urban and Schwarzenberg, 1988.

Chaney, D. M.; Lee, M. S.; Khan, M. A.; Krueger, W. A.; Mandracchia, V. J. \& Yoho, R. M. Study of ten anatomical variants of the foot and ankle. J. Am. Podiatr. Med. Assoc., 86:532-7, 1996.

Claassen, H. \& Wree, A. Isolated flexor muscles of the little toe in the feet of an individual with atrophied or lacking 4th head of the M. extensor digitorum brevis and lacking the 4th tendon of the M. extensor digitorum longus. Ann. Anat., 185:81-4, 2003.

García-González, A.; Bayod, J.; Prados-Frutos, J. C.; Losa-Iglesias, M.; Jules, K. T.; Vallejo, R. B. B. \& Doblaré, M. Finiteelement simulation of flexor digitorum longus or flexor digitorum brevis tendon transfer for the treatment of claw toe deformity. J. of Biomechanics., 42:1697-704, 2009.

Hartrampf, C. R. Jr.; Scheflan, M. \& Bostwick, J. 3rd. The flexor digitorum brevis muscle island pedicle flap: a new dimension in heel reconstruction. Plast. Reconstr. Surg., 66:264-70, 1980.

Ikuta, Y.; Murakami, T.; Yoshioka, K. \& Tsuge, K. Reconstruction of the heel pad by flexor digitorum brevis musculocutaneous flap transfer. Plast. Reconstr. Surg., 74:86-96, 1984.

Lin, S. D.; Chou, C. K.; Yang, C. \& Lai, C. S. Reconstruction of plantar heel defect using reinnervated, skin-grafted flexor digitorum brevis flap. Br. J. Plastic. Surg., 44:109-12, 1991.

Lobo, S. W.; Menezes, R. G.; Mamata, S.; Baral, P.; Hunnargi, S.; Kanchan , T.; Bodhe, A. V. \& Bhat, N. B. Phylogenetic variation in flexor digitorum: a Nepalese cadaveric study. Nepal. Med. Coll. J., 10: 230-2, 2008.
Nathan, H. \& Globe, H. Flexor digitorum brevis - anatomical variations. Anat. Anz., 135:295-301, 1974.

Reeser, L. A.; Susman, R. L. \& Stern, J. T. Jr. Electromyographic studies of the human foot: experimental approaches to hominid evolution. Foot Ankle, 3:391-407, 1983.

Romanes, G. R. Cunningham's manual of practical Anatomy, volume 1: upper and lower limbs. $15^{\text {th }}$ Ed. Oxford University press, 1986.

Rosse, C. \& Gaddum-Rosse, P. Hollinshead's Textbook of Anatomy. 5th Ed. Philadelphia, Lippincott- Raven 1997.

Sakai, N.; Yoshida, T. \& Okumura, H. Distal plantar area reconstruction using a flexor digitorum brevis muscle flap with reverse-flow lateral plantar artery. Br. J. Plastic Surg., 54:1703,2001 .

Sooriakumaran, P. \& Sivananthan, S. Why does man have a quadratus plantae? A review of its comparative anatomy. Croat. Med. J., 46:30-5, 2005.

Stevenson, T. R.; Kling, T. F. Jr. \& Friedman, R. J. Heel reconstruction with flexor digitorum brevis musculocutaneous flap. J. Pediatr. Orthop., 5:713-716, 1985.

Susman, R. L. Evolution of the human foot: evidence from PlioPleistocene hominids. Foot Ankle, 3:365-76, 1983.

Tokioka, K.; Nakatsuka, T.; Tsuji, S.; Ishida, K.; Obana, K. \& Osawa, K. Surgical correction for curly toe using open tenotomy of flexor digitorum brevis tendon. J. Plast. Reconstr. Aesthet. Surg., 60:1317-22, 2007.

Williams, P. L.; Bannister, L. H.; Berry, M. M.; Collins, P.; Dyson, M. \& Dussek, J. E. Gray's Anatomy: The anatomical basis of medicine and surgery. $38^{\text {th }}$ Ed. New York, Churchill Livingstone, 2000.

Yalçin, B. \& Ozan, H. Some variations of the musculus flexor digitorum brevis. Anat. Sci. Int., 80:189-92, 2005.

\author{
Correspondence to: \\ Dr. Isurani llayperuma, Ph.D. \\ Department of Anatomy, \\ Faculty of Medicine, \\ University of Ruhuna, \\ P.O.Box 70, Galle, \\ SRI LANKA.
}

E-mail: iisurani@yahoo.com

Received: $30-10-2010$

Accepted: 16-10-2011 